\title{
Angina Indicative of Malignant Hemopathies: About Two Cases
} \author{
Siga Evelyne $^{2}$ and Manga Noel Magloire ${ }^{5}$ \\ ${ }^{1}$ Medical Analysis Laboratory at the Ziguinchor Peace Hospital, Assane Seck University of Ziguinchor, Senegal \\ ${ }^{2}$ ENT-CCF Department of the Ziguinchor Peace Hospital, Assane Seck University of Ziguinchor, Senegal \\ ${ }^{3}$ Anatomy and Pathological Cytology Laboratory at Assane Seck University of Ziguinchor, Senegal \\ ${ }^{4}$ Clinical Hematology Service of the National Blood Transfusion Center of Dakar, Senegal
}

Coly Mame Ngoné ${ }^{1}$, Ndadi Tchiengang Kadielle Junie ${ }^{2 *}$, Senghor Fabrice ${ }^{3}$, Effa Nsah Gaston ${ }^{4}$, Kane Yaya ${ }^{5}$, Diom

${ }^{5}$ Nephrology - Infectious Diseases - Internal Medicine Department of the Ziguinchor Peace Hospital, Assane Seck University of Ziguinchor, Senegal

Submission: April 13, 2021; Published: May 20, 2021

*Corresponding author: Ndadi Tchiengang K Junie, ENT and CCF Service, Ziguinchor Peace Hospital, Senegal

Summary

The malignant hemopathies can affect the pharynx tissues. It can manifest as necrotic and ulcerative damages of the pharyngeal mucosa. Although nonspecific, angina can indicate a malignant hemopathie. In front of a dragging tonsillitis associated with a persistent fever, the otolaryngologist (ENT) should request a hematologic assessment for an etiology search. We report a case of acute leukemia with myelofibrosis and a case of acute monoblastic leukemia revealed by tonsillitis.

Keywords: Malignant hemopathies; Pharynx tissues; Leukemia; Tonsillitis

\section{Introduction}

The malignant hemopathies are all cancers of the blood and lymphoid organs. They result from the proliferation of mature or immature blood cells [1,2]. Angina is one of the manifestations seen in these conditions [3]. In a study of severe hemopathies, phlegmonous angina was one of the reasons why a severe hemopathy was diagnosed immediately after going to the emergency department [4]. A Brazilian study reported $3.7 \%$ of cases of tonsillitis as the initial diagnosis of malignant hemopathie [5]. The literature also reports cases of mastoiditis, peripheral facial paralysis, submaxillitis, parotitis, cervical lymphadenopathy as initial diagnoses of malignant hemopathies [6-8]. Otorhinolaryngology (ENT) manifestations are thus frequent in malignant hemopathies. Whether or not they reveal the disease, they are rarely suggestive because their symptoms are polymorphic and non-specific [8,9]. These manifestations are sometimes inaugural, posing the problem of their etiology. The diagnosis can be guided by epidemiological and clinical arguments, but at first glance, a simple hematological assessment (hemogram) and an anatomopathological examination point to a malignant hemopathy $[8,9]$. The myelogram will make the diagnosis [2]. The treatment is carried out in a hematology department, while having previously taken care of the infection of the ENT sphere
[10]. We report two cases of malignant hemopathies: an acute leukemia with myelofibrosis and acute monoblastic leukemia revealed during the course of the angina treatment.

\section{First observation}

It was a 23-year-old young man, with no pathological history, hospitalized in the internal medicine department of the Ziguinchor Peace Hospital for persistent dyspnea. He also complained of odynophagia for more than 3 weeks and of gingivorrhagia. There was a general condition distortion at WHO stage III and fever at $39^{\circ} \mathrm{C}$. An ENT opinion was requested and in ENT examination, we noted hypertrophied bilateral palatal tonsils, highly inflammatory and ulcerated, a uvula edema, and ecchymotic lesions on the soft palate. The cervical ganglionic areas were free and the rest of the ENT examination was unremarkable. Symptomatic treatment with analgesics was started. Two days later, due to the persistence of angina, a complete hemogram was requested. That revealed pancytopenia with deep anemia $(\mathrm{Hb}=5.8 \mathrm{~g} / \mathrm{dl})$, normochromic normocytic, thrombocytopenia (platelets $=3000 / \mathrm{mm}^{3}$ ) and leukopenia (white blood cells $=3600 / \mathrm{mm}^{3}$ ). The reticulocyte level examination $\left(20,520 / \mathrm{mm}^{3}\right)$ revealed aregenerative anemia, suggesting malignant hemopathy. The patient was immediately transferred to the clinical hematology service of the national 


\section{Global Journal of Otolaryngology}

blood transfusion center in Dakar. The realization of a myelogram showed a drastic decrease in the different cell lines of the hematopoietic tissue. The diagnostic hypothesis of acute leukemia with myelofibrosis was retained. The patient died a few days later, before performing a bone marrow biopsy that would have confirmed panmyelosis (Figure 1).

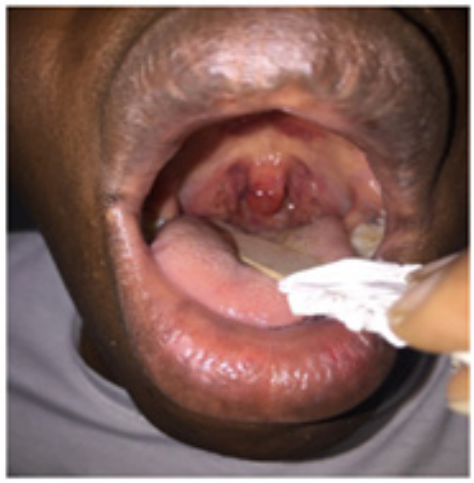

Figure 1: Oropharynx with inflammatory and ulcerated palatal tonsils, an edematous uvula, ecchymotic lesions on the soft palate.

\section{Second observation}

He was a 45-year-old man with no notable pathological history, received in the ENT department of the Ziguinchor Peace Hospital for supralaryngeal dyspnea and unbearable odynophagia that had been evolving for about two weeks. General examination revealed mucocutaneous paleness, general condition distortion at WHO stage III, and persistent fever at $39.5^{\circ} \mathrm{C}$. The ENT examination showed a congestive oropharynx, enlarged bilateral palatal tonsils almost contiguous, almost obstructing the oropharynx, with whitish puncture-shaped deposits and a very swollen uvula. The cervical ganglionic areas were free and the rest of the physical examination was unremarkable. The classic antibiotic treatment based on amoxicillin-clavulanic acid did not give a favorable result to his condition after 7 days of treatment. The retroviral serology was negative. A routine hemogram was requested. He showed bicytopenia with normochromic normocytic anemia $(\mathrm{Hb}=8 \mathrm{~g} /$ $\mathrm{dl}$ ), hyperleukocytosis at $120,000 / \mathrm{mm}^{3}$ and thrombocytopenia at $78,000 / \mathrm{mm}^{3}$ with blood blastosis at $87 \%$ thus suggesting acute leukemia. The patient was immediately transferred to the clinical hematology service of the national blood transfusion center in Dakar. The realization of the myelogram showed a proliferation of monocytoid blast-like cells at 55\% showing an acute myeloid leukemia type 5 of the FAB classification. The patient unfortunately died before treatment (Figure 2).
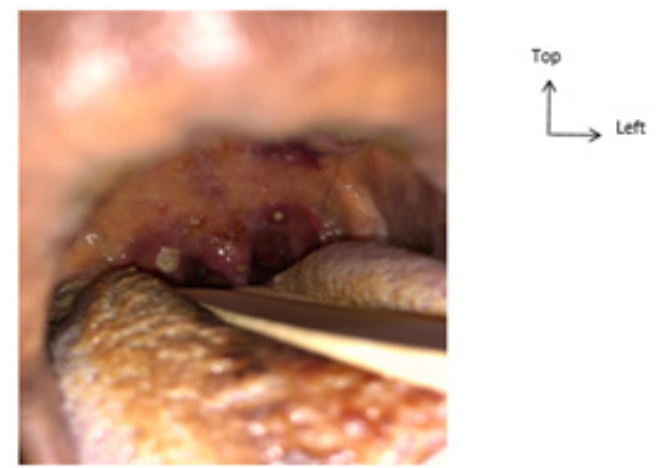

Figure 2: Enlarged palatal tonsils with whitish deposits, an edematous uvula and petechiae on the soft palate.

\section{Discussion}

In her study, Cissoko stated that the most frequent malignant hemopathy were those developed at the expense of lymphoid tissue (76.51\%) [1]. In our 2 patients the palatine tonsils were affected. The tonsils are in fact lymphoid organs belonging to the Waldeyer's ring [11]. Acute leukaemias are malignant hemopathies 
characterized by the monoclonal proliferation in the bone marrow of more than $20 \%$ of the lymphoid blast cells (ALL) or myeloid (AML) lineage [9]. The frequency of AML increases exponentially beyond the age of 40 [9]. The second patient with AML was 45 years old. Cissoko also stipulated that the predominance was male in most malignant hemopaties [1]. Malignant hemopaties can affect the tissues of the pharynx. Necrotic and ulcerative damage to this mucous membrane are sometimes the manifestations. Inflammation of the pharyngeal mucosa occurs and a severe odynophagia unresponsive to conventional therapy [10]. These clinical manifestations are the consequence of the inhibition of hematopoiesis correlated normal process with the proliferation and accumulation of monoclonal malignant cells [12]. In acute monoblastic leukemia (case of the second patient), tumor proliferation is manifested at the oropharyngeal level. Since these oropharyngeal lesions have no pathognomonic character of a malignant hemopathy, they must be placed in a precise clinical and biological context [13-15].

ENT manifestations are sometimes inaugural, posing the problem of their etiology; hence, the importance of knowing the different aspects in order to organize the best treatment [9] In acute leukemia, tonsillitis is one of the first disease manifestations in patients [10]. Our two patients were hospitalized for hyperalgesic throat infections resistant to the usual treatment, which, after investigation, eventually revealed malignant hemopathies. Gérand [2] reported in his study that it is essential for the dental surgeon to know how to identify the oral manifestations of malignant hemopathies in order to know how to refer the patient so that he receives the best possible treatment. This can lead to an increase in the patient life expectancy and a decrease in the frequency and severity of complications. The same must be true for the otolaryngologist. Among 69,3\% of patients referred by doctors (all specialties combined) for the malignant hemopathies treatment, to the G-spot hematology service of Mali, $4.4 \%$ of them were referred by ENTs and $4,9 \%$ by internists [1]. Apart from pharyngeal manifestations, other associated clinical manifestations should sound the alarm: medullar failure syndrome manifested by anemic syndrome; Hemorrhagic syndrome due to thrombocytopenia; a deterioration of the general condition with a fever of inflammatory origin, a tumor syndrome linked to tissue tumor infiltration. Our patients presented most of these associated signs [2].

Although the basic lesions observed in the various haematological pathologies are not pathognomonic of a specific entity, they can most often guide the diagnosis very early. The diagnosis of malignant hemopathy will only be made following the results of additional examinations [2,9]. A fever resistant to antibiotic treatment or resistant ENT pain, may reveal a malignant hemopathy disease and should be looked for an abnormality of the granular line (hyperleukocytosis or neutropenia) by performing an NFS [16]. The complete hemogram will detect quantitative and qualitative abnormalities in the blood [2]. Hematological assessment (hemogram and myelogram to perform a cytological examination), pathological examination (of a biopsy specimen) remains decisive in the diagnosis [2,9].

In our second patient, performing a hemogram made it possible to objectify bicytopenia, orienting the diagnosis towards malignant hemopathy. The myelogram confirmed this blood disease. It was an acute myeloid leukemia. The diagnostic approach was the same in our first patient. The clinical examination and myelogram pointed to acute leukemia with medullary fibrosis. In this case, bone marrow biopsy would have confirmed panmyelosis [17]. The patient died before this examination was performed. The death of our two patients raises questions about the survival of patients with malignant hemopathies. Cissoko, who used the Meier kapplan survival curve in her study, concluded that $65 \%$ of patients died within one year of being diagnosed with malignant hemopathy [1].

\section{Conclusion}

Recognizing the ENT manifestations of a malignant hemopathy is essential for an early diagnosis. Although not specific, they can be inaugural. The pharynx being the site of predilection of certain malignant hemopathies, ENT should be aware that any throat infection resistant to usual treatments associated with persistent fever should alert and systematically perform a hemogram. The hemogram will direct towards a malignant hemopathy and the doctor will transfer the patient to a hematology service for subsequent treatment. These clinical cases underline the importance of the multidisciplinary nature of a patient treatment with malignant hemopathy. Given the rapid development of these severe blood diseases, it is important that the patient quickly enter the chain of care, otherwise these chances of survival are reduced.

\section{References}

1. Cissoko Lala N'Drainy Sidibé (2005) Epidemiological characteristics of malignant hemopathies in the medical hematology-oncology and internal medicine departments of the Point G hospital. Doctoral thesis in medicine. Faculty of Medicine, Pharmacy and Odontostomatology, University of Bamako, Mali.

2. Mathilde G (2018) Oral manifestations of leukemia and lymphoma. Volume 1, Early Diagnosis. Thesis for the state diploma of Doctor of Dental Surgery. Faculty of Dental Surgery. Paris Descartes University, France.

3. Bordessoule D (2010) Aplasia Pathology of the hematopoietic stem cell. Aplasia.

4. Dang AT, Signol N, Bennett EP (2015) Severe hemopathies revealed in adult emergency departments: single-center study of 108 patients. Ann Fr Med Emergency 5: 311-319.

5. Teresa Cristina, Jose Barreto (2007) Osteoarticular Manifestations as Initial Presentation of Acute Leukemias in Children and Adolescents in Bahia, Brazil. J Pediatr Hematol Oncol 29(9).

6. Vigiera S, Nicollasa R, Roman S (2013) Atypical acute mastoiditis revealing Burkitt's leukemia in a 7-month-old child. Pediatric Archives 20: 1317-1320. 
7. Randriamidona Banjamina (2005) Clinical aspects of acute myeloblastic leukemia observed in the CHU of Antananarivo. Doctoral thesis in medicine. Antananarivo Faculty of Medicine, Antananarivo University, Madagascar.

8. S Trabelsi, S Tababi, L Ouertatani (2006) ENT manifestations revealing acute leukemia in relation to three observations. J Tun Orl.

9. Brette MD, Monteil JP (2004) Otorhinolaryngological manifestations of blood diseases in adults. Medical-Surgical Encyclopedia 20-915-A-10, p. 1-11.

10. Palchun VT, Kryukov AI (2001) Angina with leukemia. Otorhinolaryngology: a guide for doctors. Part 2, medical portal "MedguideBook".

11. French College of ENT and Cervico-Facial Surgery (2014) Item 146 (ex-item 77): Angina in adults and children, and nasopharyngitis in children. (C) UMVF - Francophone Virtual Medical University, France.

12. Doumbia M, Uwingabiye J, Bissan A, Rachid R, Benkirane S, et al. (2016) Epidemiological, clinical, cytological and immunophenotypic aspects of acute leukemia in children: experience of the hematology laboratory of the IBN Sina University Hospital Center. Pan African Medical Journal 23: 258
13. Nikiema MW (2020) Contribution of the myelogram to the diagnosis of hemopathies at the Yalgado Ouedraogo university hospital in Ouagadougou: about 175 spinal cord punctures. African and Malagasy journal of Scientific Research / Health Sciences 2(1).

14. Abdelraheem FN, Chakour M (2013) The contribution of the myelogram in the diagnosis of hemopathies About 100 cases, medical thesis, Faculty of Medicine of Marrakech, Morocco.

15. Nafil H, Tazi I, Faez S, Benchemsi N (2012) Cytological profile of acute leukemia in Casablanca. Journal Africain du Cancer / African Journal of Cancer 4(2): 79-83.

16. Lengliné E, Azoulay E (2011) Emergency management of acute leukemia. Emergencies. Chapter 65, pp. 745-757.

17. Huguet F, Récher C (2011) Acute leukaemias in adults. Hematology 17(3): 203-224.

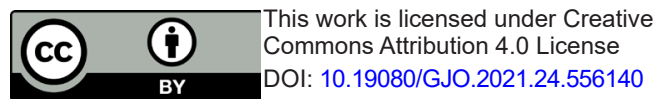

\section{Your next submission with Juniper Publishers will reach you the below assets}

- Quality Editorial service

- Swift Peer Review

- Reprints availability

- E-prints Service

- Manuscript Podcast for convenient understanding

- Global attainment for your research

- Manuscript accessibility in different formats

( Pdf, E-pub, Full Text, Audio)

- Unceasing customer service

Track the below URL for one-step submission https://juniperpublishers.com/online-submission.php 